\title{
Causes of blindness in the adult population of the Republic of Ireland
}

\author{
Alain Munier, Tim Gunning, Desmond Kenny, Michael O’Keefe
}

\begin{abstract}
Backgroundlaim-Blindness in the developed countries affects 3.5 million people. This study was conducted on the causes of blindness in the Republic of Ireland based on the register of the National Council for the Blind of Ireland. The aim was to determine the prevalence of potentially avoidable blindness and to identify its causes.

Method-Criteria for registration as blind are in Ireland: best corrected visual acuity of $6 / 60(0.1)$ or less in the better eye or a visual field restricted to 20 degrees or less. Data on 5002 adults 16 years an older registered as blind were analysed. The causes of blindness are classified in 17 diagnostic categories.

Results-The leading causes of blindness are macular degeneration and glaucoma, each accounting for $16 \%$ (812 and 795$)$. Cataract accounted for $11 \%$ (561), a third of these had an associated cause of blindness and one tenth had a cognitive deficit. Diabetic retinopathy ranked as the 11 th cause of blindness and accounted for $3 \%$ (147). More than half of the patients were 65 years and older.

Conclusion- $25 \%$ of blindness was potentially avoidable. The treatable causes were glaucoma and diabetic retinopathy in the working population and glaucoma and cataract over 65 years of age. Glaucoma is the most important, which raises the question of a screening programme. The prevalence of blindness of $3 \%$ due to diabetic retinopathy is lower than in most other series.
\end{abstract}

(Br F Ophthalmol 1998;82:630-633)

National Council for the Blind of Ireland, PV Doyle House, Dublin, Ireland

T Gunning

D Kenny

Eye Department, Temple Street

Children's Hospital, Dublin 1, Ireland

A Munier

M O'Keefe

Correspondence to: M O'Keefe, Mater Private Hospital, Eccles Street, Dublin 1, Ireland.

Accepted for publication 21 January 1998
Blindness is defined by the World Health Organisation as best corrected visual acuity in the better eye of less than $0.05(3 / 60)$ or a visual field of 10 degree or less. ${ }^{1}$ It was estimated that 38 million people in the world are blind and a further 110 million are visually impaired. $^{2}$

We conducted a study based on the national blind register in the Irish adult population. The purpose of the study was to evaluate the prevalence of potentially treatable causes of blindness and to identify these.

\section{Method}

All legally blind people are registered by the National Council for the Blind of Ireland. Criteria for legal blindness in Ireland are: visual acuity of $6 / 60(0.1)$ or worse in the better eye or a visual field restricted to 20 degrees or less in the widest diameter of vision. This corresponds with severe visual impairment as defined by the $\mathrm{WHO}^{1}$ (Table 1). Registration is granted after an ophthalmologist completes an application form giving visual acuity, field, refraction, brief details of ophthalmic procedures, ophthalmic diagnosis, and systemic diagnosis. The causes of blindness are classified in 17 different diagnostic categories and entered in a computerised register. When there is more than one cause, the patient is classified under only one diagnostic category, judged the most important one by the registering ophthalmologist.

We analysed data from this register between May and November 1996 for all people aged 16 years and older. We divided the causes of blind registration in five age groups: 16-34 years, 35-54 years, 55-64 years, 65-79 years, 80 years and over. We compared the blind population with the total Irish population of same age and sex as estimated by the March 1996 census of population (Central Statistic Office).

\section{Results}

During the study period, 5002 people aged 16 years and older were registered as blind, $0.2 \%$ of the total Irish population.

The leading causes of blindness were macular degeneration $(16.2 \%, 812$ patients) and glaucoma (15.9\%, 795 patients) (Table 2).

In the age group 16-34 years, albinism and congenital cataract accounted each for $14 \%$ (194) of registered blindness, followed by optic atrophy $(10 \%, 72)$ and retinitis pigmentosa $(9 \%, 66)$. In the age group $35-54$ years, retinitis pigmentosa accounted for $14 \%$ (142) followed by albinism $(9 \%, 93)$, cataract $(8.5 \%$, $86)$, myopia $(7 \%, 74)$, and congenital cataract $(7 \%, 68)$. In the age group 55-64 years, retinitis pigmentosa accounted for $14 \%$ (65) followed by glaucoma $(12 \%, 55)$, cataract $(12 \%$, $53)$, and myopia $(9 \%, 41)$. In the older age groups, $65-79$ years, glaucoma $(20 \%, 266)$ and macular degeneration $(20 \%, 266)$ were most important. Over 80 years of age, macular degeneration accounted for $32 \%$ (478), glaucoma for $27 \%$ (399), and cataract for $16 \%$ (231).

Glaucoma over the age of 80 years affected proportionally more males $(205 / 536=38 \%)$ than females $(194 / 950=20 \%)$.

Table 1 Definitions ${ }^{1}$

\begin{tabular}{lll}
\hline & Visual acuity & Field \\
\hline Legal blindness in Ireland & $<6 / 60$ & $<20$ degrees \\
Severe visual impairment WHO & $<6 / 60,>3 / 60$ & \\
Blindness WHO & $<3 / 60$ & $<10$ degrees \\
\hline
\end{tabular}




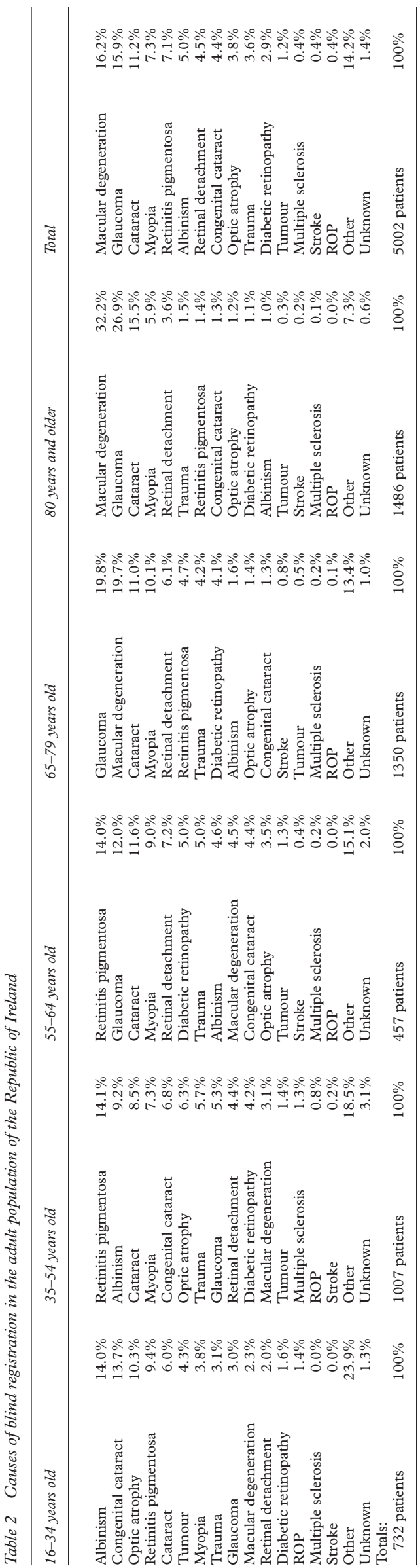

Diabetic retinopathy accounted for $3 \%$ (147) of registered blindness and had the highest proportion in the age group 55-64 years, accounting for $5 \%$ (23).

Trauma caused three times more blindness in males than in females for all age groups.

\section{Discussion}

Blindness in the developed world affects 3.5 million people. ${ }^{2}$ Two types of studies have been conducted: one based on a sample of population-for example, patients from a hospital, and the other based on a register for the blind. For both types, different definitions of blindness and different methods of evaluation make comparison difficult. Blind registration exists in most developed countries and is held by state or partially state funded organisations who provide help to the visually impaired. The registers list the people satisfying criteria for legal blindness in their country. There are limitations of register based studies. The data reflect only those who register. ${ }^{3}$ The classification of the causes of blindness often mixes anatomical and causal diagnoses so that two patients with the same pathology can be classified with two different causes-for example, retinal detachment and trauma. ${ }^{4}$ The data are per patient and not per eye and not all registration forms are completed accurately.

Data on blindness in the developed countries are limited, compared with some developing countries, which have published several large scale studies. ${ }^{245}$ However, studies have been performed in some countries such as Australia, ${ }^{6}$ Germany, ${ }^{7}$ Great Britain, ${ }^{8-12}$ Italy, ${ }^{13-15}$ and the USA. ${ }^{16}$ The leading causes of blindness reported are macular degeneration, glaucoma, cataract, and diabetes (Table 3).

More than half the patients in our study were older than 65 years and a third were over 80 years of age. This confirms the increasing frequency with older age. ${ }^{10} 1718$ Three conditions caused three quarters of the blindness in those over 80 years of age-macular degeneration, glaucoma, and cataract.

Macular degeneration accounted for a quarter of the blindness over 65 years of age. It has a prevalence of $8 \%-20 \%$. It accounts for up to half of the blindness in other studies. ${ }^{19} 20$

Glaucoma accounted for $16 \%$ (795) of adult blindness and its importance increased with age. In other studies the proportion of blindness due to glaucoma ranges from $7 \%$ to $21 \%{ }^{21}$ Glaucoma could be considered as a preventable cause of blindness. ${ }^{22}$ It requires treatment early to preserve sight. The disease is asymptomatic until very advanced. Screening is difficult in the absence of a single reliable test to detect it and the diagnosis sometimes requires an experienced clinician. No national screening programme exists in Ireland. Costing of such a programme has been investigated in England ${ }^{23}$ and could compare favourably with the cost of the blindness due to glaucoma. Our results emphasise the need for allocating resources to screening, treatment, and research on glaucoma. The higher prevalence for males (noticeable over 80 years of age with $0.62 \%$ 
Table 3 Leading causes of blindness in other studies 581013

\begin{tabular}{lcccc}
\hline & $\begin{array}{l}\text { Macular } \\
\text { degeneration }\end{array}$ & Glaucoma & Cataract & Diabetes \\
\hline Bavaria 1992 & $15 \%$ & $14 \%$ & $5 \%$ & $7 \%$ \\
Turin 1967-91 & $4 \%$ & $9 \%$ & $27 \%$ & $13 \%$ \\
Avon 1989 & $49 \%$ & $15 \%$ & $2 \%$ & $6 \%$ \\
New South Wales 1986* & $38 \%$ & $13 \%$ & $16 \%$ & $2 \%$ \\
Scotland 1980 & $30 \%$ & $15 \%$ & $10 \%$ & $9 \%$ \\
Ireland 1996 & $16 \%$ & $16 \%$ & $11 \%$ & $3 \%$ \\
\hline
\end{tabular}

^This study looked at people aged 50 and older.

Table 4 Causes of blindness in the working population

\begin{tabular}{lc}
\hline 16-64 years of age & $\%$ \\
\hline Retinitis pigmentosa & 12.6 \\
Albinism & 9.8 \\
Congenital cataract & 8.5 \\
Cataract (excluding congenital) & 8.4 \\
Optic atrophy & 7.0 \\
Myopia & 6.6 \\
Glaucoma & 6.0 \\
Trauma & 4.7 \\
Retinal detachment & 4.2 \\
Diabetic retinopathy & 3.5 \\
All other & 28.7 \\
Total & 100.0 \\
\hline
\end{tabular}

(205/33 000) compared with $0.32 \%$ (194/ 60300 ) for females in our study) had been reported before. ${ }^{24}$

Cataract surgery has undergone major technical advances making it safer and more successful. Yet it still accounts for 13\% (380) of blind registration over 65 years of age and $16 \%$ (231) over 80 years of age, and is the leading cause of blindness in some populations of the developed world. ${ }^{15}{ }^{18}$ As they were registered, these patients had access to an ophthalmologist at least once. We reviewed the medical data on every person entered with cataract as a cause of blindness in our study. Of 561 non-congenital cataracts, $195(35 \%)$ had another cause of blindness, glaucoma in 45 , age related macular degeneration in 25 and retinal detachment in 20 . Sixty four $(11 \%)$ patients with a cataract also had a mental handicap-12 (2\%) had Down's syndrome and five $(1 \%)$ had a psychiatric condition. Others ${ }^{18}$ have reported a high rate of poorer cognitive functions associated with poorer visual acuity. The benefits of cataract extraction are difficult to evaluate in these patients.

In the working population (16-64 years of age), the leading causes of blind registration were genetic (Table 4). Most of them cannot be treated with the present scientific knowledge. Prevention exists through genetic counselling. Retinitis pigmentosa and albinism accounted for $22 \%$. In addition, some of the congenital cataracts and some other disorders are also genetic. The proportion of genetic causes was higher than was found in children $(16 \%) .^{25}$

Diabetic retinopathy in our study affected $3 \%$ (147) of those registered blind. It represented the 10th cause of blindness in the working age group. In the literature it accounts for $2 \%-20 \%$ of blindness. ${ }^{4-91112142627}$ The age distribution with a maximum in the group $55-64$ years of age $(5 \%, 23)$ is similar to other studies. ${ }^{9}$ Different hypotheses can explain the low rate found in our study. Underregistration is one possible explanation. However, we cannot explain why blind diabetics would reg- ister less than those blind from other causes. Registration under another diagnostic category is possible-for example, under glaucoma when diabetic retinopathy is a complication of rubeotic glaucoma, or under retinal detachment when diabetic retinopathy is a complication of retinal detachment. The Irish population may be particularly resistant to diabetic retinopathy. Others found a lower rate of diabetic retinopathy in an Irish population with diabetes mellitus diagnosed after the age of 70 years than did studies in other countries. ${ }^{28} 29$ The authors note that a different presentation of the data may explain a lower rate, but a genuine low rate of diabetic retinopathy in the Irish diabetic population is possible. Finally, the presence of a hospital based screening programme since 1991, the availability of lasers and good medical standards may play a role.

In all, 3.6\% (181) were blind following trauma. The male to female ratio is about 3 to 1 in all age groups for traumatic blindness. Males have been reported in other studies to have a higher risk. This tendency is already apparent from childhood. ${ }^{30-32}$

In conclusion, about $75 \%$ of registered blindness is unavoidable; $25 \%$ of registered blindness follows a potentially treatable affection. In the working population (16-64 years of age), glaucoma and diabetic retinopathy are significant causes of blindness that could be avoided. In the older age groups, glaucoma and cataract are the major preventable causes of blindness. Patients over 65 years of age frequently present with associated pathologies which make their treatment more difficult.

The proportion of blindness due to diabetic retinopathy is lower than in most other studies. ${ }^{4-9} 1112142627$ We have no certain explanation. The Irish population may be less prone to develop diabetic retinopathy than others. The presence of a hospital based screening programme since 1991 is certainly favourable.

The absence of a screening programme for glaucoma underlines the importance of each ophthalmologist/optometrist/optician screening all his/her adult patients who consult for other reasons. Establishing a national screening programme may reduce the prevalence of new blindness. The cost effectiveness of such a programme remains to be proved, but preliminary estimations are favourable. ${ }^{23}$

This study also clarifies the question of blindness due to cataract, showing that one third of these patients have a cause other than cataract for blindness.

1 World Health Organisation. International classification of impairments, disabilities and handicaps. Geneva: WHO, 1980:79-85

2 Thylefors B, Negrel AD, Pararajasegaram R, et al. Global data on blindness. Bull World Health Organ 1995;73:115-21.

3 Robinson R, Deutsch J, Jones HS, et al. Unrecognised and unregistered visual impairment. Br f Ophthalmol 1994;78: 736-40.

4 Suttorp Schulten MSA, Rothova A. The possible impact of uveitis in blindness: a literature survey. $\mathrm{Br} \mathcal{F}$ Ophthalmol 1996;80:844-8.

5 Johnson GJ, Minassian DC. Prevalence of blindness and eye disease: discussion paper. F Roy Soc Med 1989;82:351-4.

6 Chan CW, Billson FA. Visual disability and major causes of blindness in NSW: a study of people aged 50 and over Ophthalmol 1991;19:265-6.

7 Krumpaszky HG, Klauss V. Erblindungsursachen in Bayern. Auswertung einer reprasentativen Stichprobe der 
Blindengeldakten aus Oberbayern. Klin Monatsbl Augenheilkd 1992;200:142-6.

8 Sorsby A. The incidence and causes of blindness in England and Wales 1963-68. Department of Health and Social Security. Report on public and medical subjects No 128

9 Ghafour IM, Allan D, Foulds WS. Common causes of blindness and visual handicap in the west of Scotland. $\mathrm{Br} f$ Ophthalmol 1983;67:209-13.

10 Bruce IW, McKennell AC, Walker EC. Blind and partially sighted adults in Britain: the RNIB survey. Vol 1. London: HMSO, 1991.

11 Grey RHB, Burns Cox CJ, Hughes A. Blind and partial sight registration in Avon. Br F Ophthalmol 1989;73:88-94.

2 Aclimandos WA, Galloway NR. Blindness in the city of Nottingham (1980-1985). Eye 1988;2:431-4.

13 Nicolosi A, Marighi PE, Rizzardi P, et al. Prevalence and causes of visual impairment in Italy. Int $\mathcal{J}$ Epidemiol causes of visual

14 Porta M, Tomalino MG, Santoro F, et al. Diabetic retinopathy as a cause of blindness in the province of Turin, north west as a cause of blindness in the province of Turin, noth

15 Ponte F, Giuffre G, Giammanco R. Prevalence and causes of blindness and low vision in the Casteldaccia Eye Study. Graefes Arch Clin Exp Ophthalmol 1994;232:469-72.

16 Leibowitz HM, Krueger DE, Maunder LR, et al. The Framingham Eye Study Monograph. Surv Ophthalmol (suppl) 1980;24:335-610.

17 Tielsch JM, Sommer A, Witt K, et al. Blindness and visual impairment in an American urban population. The Baltimore Eye Survey. Arch Ophthalmol 1990;108:286-90.

18 Tielsch JM, Javitt JC, Coleman A, et al. The prevalence of blindness and visual impairment among nursing home residents in Baltimore. N Engl f Med 1995;332:1205-9.

19 Klein R, Klein BEK, Linton KLP. Prevalence of age related maculopathy. The Beaver Dam Eye Study. Ophthalmology 1992;99:933-43.
20 Vingerling JR, Dielemans I, Hofman A, et al. The prevalence of age related maculopathy in the Rotterdam Eye Study. Ophthalmology 1995;102:205-10.

21 Thylefors B, Negrel AD. The global impact of glaucoma. WHO Bull 1994;72:323-6.

22 Pitts Crick R. Chronic glaucoma a preventable cause of blindness. Lancet 1974;1:205-7.

23 Jones SJ, Vernon SA, Cater L, et al. Costing a community based screening programme for the detection of glaucoma. Eye 1990;4:98-102.

24 Leske MC. The epidemiology of open angle glaucoma: a review. Am F Epidemiol 1983;118:166-91.

25 Goggin M, O'Keefe M. Childhood blindness in the Republic of Ireland: a national survey. $\mathrm{Br} \quad \mathcal{f}$ Ophthalmol 1991;75:425-9.

26 Myers FL. Diabetics: a new growing and special contingent of cases. In: Hoene CW, Cull JG, Hardy RE, eds. Ophthalof cases. In: Hoene CW, Cull J G, Hardy RE, eds. Ophthalmological considerations in the rehabilitation of

27 Thompson JR, Du L, Rosenthal AR. Recent trends in the registration of blindness and partial sight in Leicestershire. Br F Ophthalmol 1989;73:95-9.

28 Cahill M, Halley A, Codd M, et al. Prevalence of diabetic retinopathy in patients with diabetes mellitus diagnosed after the age of 70 years. $B r F$ Ophthalmol 1997;81:218-22.

$29 \mathrm{WHO} / \mathrm{IDF}$ Europe. Diabetes care and research in Europe: the Saint Vincent Declaration. Diabetic Med 1990;7:360.

30 Thylefor B. Epidemiological patterns of ocular trauma. Aust NZ F Ophthalmol 1992;20:95-8.

31 Katz J, Tielsch JM. Lifetime prevalence of ocular injuries from the Baltimore Eye Survey. Arch Ophthalmol 1993;111: 1564-8.

32 Takvam JA, Midelfart A. Survey of eye injuries in Norwegian children. Acta Ophthalmol Copenh 1993;71: $500-5$. 